\title{
Collaborative Environmental Governance: Achieving Collective Action in Social-Ecological Systems
}

\author{
Örjan Bodin ${ }^{1 *}$ \\ ${ }^{1}$ Stockholm Resilience Centre, Stockholm University, 10691 Stockholm, Sweden \\ *Correspondence to: orjan.bodin@su.se
}

This is the author's version of the work. It is posted here by permission of the AAAS for personal use, not for redistribution. The definitive version was published in Science in August 2017 (Volume 357, issue 6352), DOI: 10.1126/science.aan1114. The published article can be found here: https://science.sciencemag.org/content/357/6352/eaan1114

\begin{abstract}
Managing ecosystems is challenging due to high numbers of stakeholders, permeability of man-made political and jurisdictional demarcations vis-à-vis the temporal and spatial extent of biophysical processes, and a limited understanding of complex ecosystem and societal dynamics. Given these conditions, collaborative governance is commonly put forward as the preferred means of addressing environmental problems. Under this paradigm, a deeper understanding of if, when, and how collaboration is effective, and when other means of addressing environmental problems are better suited, is needed. Interdisciplinary research on collaborative networks demonstrates that which actors get involved, with whom they collaborate, and in which ways they are tied to the structures of the ecosystems has profound implications on actors' abilities to address different types of environmental problems.
\end{abstract}

\section{Introduction}

Ecosystems constitute complex entities spanning geographical and temporal scales typically not wellaligned with various man-made jurisdictional and political demarcations. Hence, the ability to match the scale and extent of ecosystems with appropriate structures of governance suffers from institutional fragmentation (1). These considerations are at the heart of the research on institutional (or socialecological) fit (2-6), and cross-border and cross-scale collaboration is often seen here as a means by which to overcome such institutional fragmentation $(7,8)$. Furthermore, ecosystems are characterized by uncertainties and emergent behaviors (9). Therefore, developing better knowledge of ecosystem dynamics through continual learning is considered to be of key importance in environmental governance $(1,10)$. Collaboration is, in this realm, put forward as a means by which to (i) enhance the generation of new knowledge through social learning $(9,11)$, (ii) better integrate important insights from different knowledge systems (12), and (iii) diffuse knowledge and best practices among a multitude of actors (13). Also, governance of ecosystems involves balancing actors' different interests. If not, asymmetry of power and influence among different advocacy coalitions can, for example, lead to governance inertia 
inhibiting effective measures to deal with environmental problems $(14,15)$. A common argument here is that collaboration across opposing coalitions can help to unlock such governing deadlocks $(16,17)$.

Arguments in favor of multi-actor collaboration in addressing environmental problems are plentiful and stretch across many different fields of research $(8,10,18)$. This broad and multifaceted research uses different terminologies and perspectives. The term collaborative environmental governance is used here to capture collaborative approaches to environmental management in a general and inclusive sense. Although the arguments in favor of collaboration, and the studies supporting these claims, are numerous, there is also ample evidence that collaboration does not always deliver substantial benefits. Hence, there are reasons to caution against collaboration as an all-encompassing mode of government for all kinds of challenges (19). For example, it can be very time-consuming for a group of actors with different backgrounds and interests to overcome initial collaborative barriers $(20,21)$. Hence, since some pressing environmental problems call for immediate action, mitigation through multi-actor collaboration might not always be the most feasible option. Further, in practice actors often decide for themselves who they wish to collaborate with, what they want to accomplish, and in what types of collaborative venues $(1,22)$. Hence, governance through multi-actor collaboration is, as compared to more traditional and bureaucratic modes of government, encumbered with critical issues pertaining to various democratic qualities such as transparency of decision-making procedures, legitimacy and accountability, and procedural fairness (23). Managing collaborative environmental governance initiatives therefore presents public managers with novel leadership challenges $(24,25)$.

The environmental issue of concern might be so highly contested and riddled with issues of asymmetries of power among the stakeholders that hoping for collaboration as a means of solving environmental problems is quite simply naïve $(26,27)$. Studies of policy change have shown that collaboration in highly contested policy issues does not have any substantive impact. For example, no substantial changes in Swiss nuclear energy policies occurred during the years 2001-2006 although the three opposing actors coalitions did collaborate relatively intensively (15). Further, although the federally supported groundwater management partnership in the Verde River Basin in USA has instigated actors with conflicting interests to collaborate in e.g. sharing information, this has not lead to any substantial changes in values and beliefs (28). This in turn has hindered the actors from jointly taking any significant steps towards generating mutually agreeable management options.

Also, there have been cases showing that a striving towards enhanced collaboration could in itself escalate conflicts (29). Therefore, collaborative initiatives which are unable to address conflicts of interests and deliberate in finding some form of middle ground can fall short of producing anything other than a reinforcement of the current status quo (30). Alternatively, they might fall short of delivering anything other than a simple compilation of the actors' own wish lists or a simple agreement on vague and non-committal declarations largely concealing fundamental tradeoffs and contradictions (31).

The rapid uptake and roll-out of collaborative approaches to governance across different contexts (32, 33) has also created significant uncertainty and variability among actors with regards to why they collaborate, what exactly they are supposed to (or want to) accomplish, and together with whom (cf. , 34). This can result in actors spending considerable time and resources on "networking" leading to a high turnover of social ties, although this does not necessarily lead to increased governance performance. For example, increased networking among planners engaged in enhancing Swedish municipalities' preparedness to forthcoming natural disasters is seemingly not leading to increased performance (35). 
The specific types of social ties actors develop while engaging in collaboration also impact collaborative outcomes. For example, social ties utilized to merely exchange information can facilitate social learning albeit being ineffective in enabling any behavioral change (36), whereas social ties that build on deeper relations like friendship can facilitate such changes (37).

\section{A integrated network-centric framework}

Collaboration thus seems like an appealing and often necessary, but not in itself sufficient, modus operandi in addressing many of today's environmental problems. Put bluntly, the issue is clearly not as simple as meaning that all we need to do is to establish collaboration among a large set of actors and stakeholders, and then all is good. The question is rather when and how collaboration is effective, for what kind of environmental problems, and if and how this relates to the temporal and spatial characteristics of the governed ecosystems.

One way of approaching this puzzle is through the lenses of the participating actors and the ways in which they engage in collaboration with others. This implies directing attention to who the actors are, with whom they collaborate, and how the structures of such collaborative networks relate to the actors' abilities to address different environmental problems $(38,39)$. Recent years have shown a rapid increase in studies investigating whether or not various environmental problems have instigated the formation of collaborative networks, and if so, how these are formed. In addition, al beit to a lesser extent, studies have also investigated how these different forms impact the ability to address different types of environmental problems. This is by no means the only way in which to study collaborative environmental governance. However, it provides a means of investigating different collaborative processes following a bottom-up approach (examining if, how and why actors engage in different kinds of collaboration with certain others) while simultaneously providing an analytical vehicle for investigating collaborative performance at the group level (examining relationships between different collaborative network characteristics and collective abilities to solve environmental problems). Hence, a collaborative network perspective thus constitutes a framework that helps cross-fertilizing insights across different studies and fields of research. Networks can be characterized in numerous ways, although characteristics often being at focus are: (i) degree of network cohesiveness (e.g. density of relations), (ii) degree of network centralization (the extent to which one or a few actors act as hubs), (iii) degree of network fragmentation (i.e. if and to what extent the network consists of different subgroups), and (iv) degree of connectivity across different types of actors (i.e. homophily and heterophily)(Fig. 1A-C).
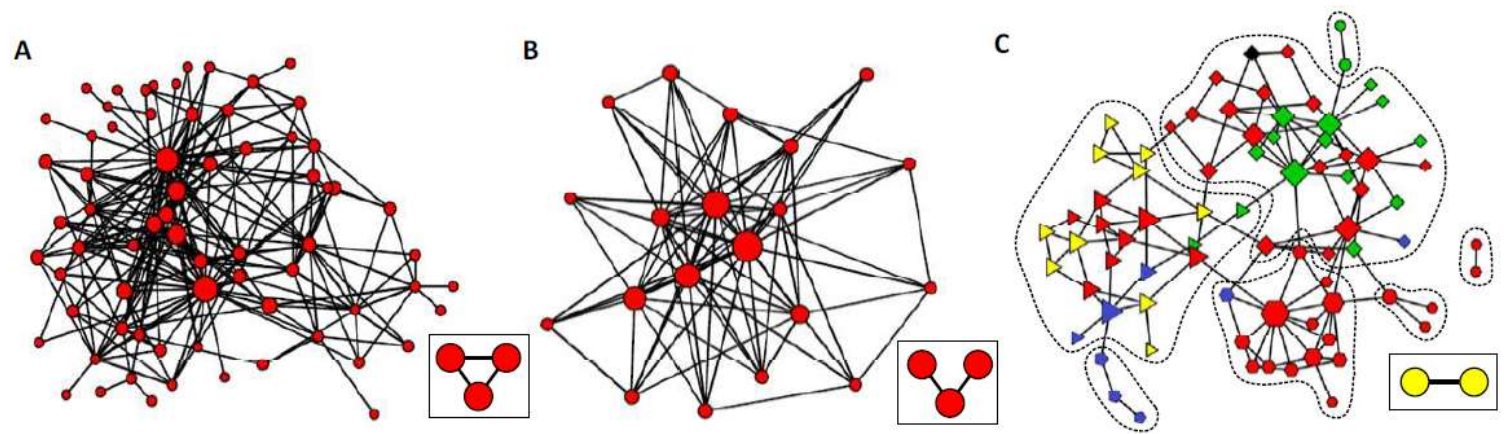

Fig. 1: Different structural network characteristics. (A) represents a cohesive collaborative network comprising numerous collaborative ties between actors engaged in coastal zone management in Sweden (40). The differences between the most and the least connected actors are relatively small, and the 
closed triangular structure (inset) is a common building block in this network ("two friends of a common friend also tend to be friends"). The centralization score is 0.26 (on a range from 0 to 1 ), and the modularity index that captures the extent to which the network consists of subgroups peaks at 0.07 (on a range from 0 to 1). (B) represents a centralized collaborative network from a UNESCO Biosphere reserve in Canada (41), where the differences in centrality between the most and least connected actors differ substantially. The open triangular structure (inset) is a common building block in this network (an actor connects two otherwise unconnected actors). The centralization score is 0.63 and the modularity index is approximately 0 . (C) represents a more compartmentalized collaborative network of small-scale fishermen in east Africa (42). The colors represent fishermen using different gears, and the dotted lines shows different identified cohesive subgroups. The subgroups partly coincide with gear types. The building block capturing two socially connected actors using the same gear (inset) is common in this network. The centralization score is 0.11 , and the modularity index peaks at 0.58 .

A key factor that distinguishes environmental problems from many other collective action problems in general, is that environmental problems are inevitably tied to the complex structures and processes of boundary-spanning ecosystems. Thus, effective and long-lasting solutions to environmental problems require these ecosystem characteristics to be explicitly taken into account $(9,43)$. However, it is not uncommon that studies of collaborative environmental governance are entirely focused on the social and political processes, and the specifics of the ecosystem being the target for the collaborative efforts are largely disregarded. This is not to say that these studies are missing the point. On the contrary, these processes are of crucial importance for any kind of collaborative undertaking. However, these studies do not investigate if and in what ways the specific biophysical characteristics of the ecosystems pose any constraints with regards to how collaborative arrangements should ideally be devised. Hence, taking stock in the large body of research on social-ecological fit arguing there is no "one-size-fits-all" governance arrangement that works well across all possible social-ecological contexts $(2-6,44)$, it seems crucially important to advance understanding regarding how well a collaborative arrangement 'fits' to the specifics of the environmental problem being addressed. Recent theoretical and methodological innovations in multilevel network analyses have made headway in facilitating interdisciplinary inquiries where both social and ecological dimensions of collaborative environmental governance are analyzed together (45-48). Therefore, an explicit network perspective on collaborative environmental governance can be used as an integrated framework in investigating which social structures and processes are conducive to addressing which kinds of environmental problems, in which kinds of biophysical contexts.

\section{Fit to the collective action problem}

\section{Collaborative learning}

Many, if not most, environmental problems can be characterized as collective action problems. However, collective action problems come in different shades. A key argument in favor of collaboration is, for example, how it facilitates learning (10). Learning is here conceived as a collective action problem where processes involving sharing experiences and engaging in collective deliberation are in focus (social learning, see e.g. (11)). For such processes to materialize, actors need be socially linked with others in suitable ways. Learning about complex problems typically requires of the actors to draw from a range of knowledge domains and expertize, which differs substantially from learning about problems that are well confined within a specific knowledge domain (cf. inter-versus intra-disciplinary research). Addressing complex problem is benefited by actors with different educational backgrounds, roles, and occupations coming together; therefore a strong tendency of similar actors flocking together in isolated 
subgroups could be detrimental (cf. Fig. 1C). Actors only interacting within their own subgroups easily develop their own subcultures with a sense of 'us-and-them', and different and often incompatible perceptions of the problems at hand and how to best solve them emerge between the subgroups (14, 15, 49-51). For example, it has been shown that limited interaction between subgroups of tuna-fishers have suppressed collective learning, which has led to suboptimal harvesting practices (52). In contrast, a study of collaborative coastal zone management suggests that collaborative networks where heterogeneous actors are not confined to isolated subgroups only consisting of their immediate peers facilitate learning about complex problems such as how to accomplish ecosystem-based management (40). However, it was also indicated that a similar learning effect could be accomplished through facilitation by actors occupying central positions in the collaborative networks.

Learning about problems that are less complex, typically confined within a specific knowledge domain, does not necessarily benefit from bringing together a heterogeneous set of actors. Instead, here it is often more relevant to frame the learning process as a process of diffusion. The specific structural characteristics of social networks well suited for diffusion constitute a research field by itself (53), although the positive effect of collaborative networks characterized by high densities of social ties for the spread of new management practices in environmental governance has been empirically demonstrated $(37,54)$.

A key component in addressing many environmental problems is the ability to innovate new solutions to sometimes old problems (55). Innovation can be framed as a result of learning, although with more emphasis on learning favoring deliberation and thinking "out-of-the-box". This largely resembles the challenge of addressing complex problems. However, since novelty in parts implies breaking with current established norms and perceptions, an overly cohesive collaborative network could contribute to the reinforcement of current perceptions thus making it more difficult for new ideas to emerge and find support (56). This has been demonstrated among farmers in Australia where those who instigated more transformative farming practices were part of further-reaching but sparser collaborative networks as compared to those who were more prone to incremental changes (57). This also touches upon the classic work by Granovetter where he showed that far-reaching and weak social ties are more important when people are seeking novel information (58).

\section{Coordination or cooperation}

Although learning is of crucial importance in governing complex ecosystems, it is what the actors' actually do that matters to the environment. Many collective action problems can be divided into two broad classes, coordination versus cooperation problems. The former describes a situation where all or most actors agree on what they want to accomplish, and getting there is more a matter of orchestrating the actors' different activities in efficient ways (59). Joint efforts to eradicate an invasive salt marsh cord grass species in the San Francisco Bay in California serves as an example of a coordination problem (60). The latter corresponds to problems where actors display different opinions and interests, and where problem solving would by necessity involve negotiations and deliberations in order to reach common agreements. Often this implies that actors will have to retract a bit from what they would ideally prefer in terms of, for example, resource utilization. A special class of cooperation problem is when there are inherent tradeoffs, which can be framed as a distribution problem (1). Accomplishing sustainable harvest levels in multinational high-sea fisheries where multiple actors compete for a limited resource serves as an example of a cooperative distribution problem (17). Further, coordination and cooperation problems have been framed as low-risk and high-risk, respectively (61). Risk was originally framed as the risk for actors defecting, but has evolved to a broader conceptualization of risks in collaborative 
endeavors (62). Several empirical studies support the notion of coherent and dense collaborative network structures being better in addressing high-risk cooperation problems whereas more centralized and sparse networks do better for low-risk coordination problems. More specifically, a network conducive to managing cooperation problems is characterized by actors tending to reciprocate incoming social ties, and to form triadic structures (two friends of a friend will also be friends, see Fig. 1A). These dense structures help to exert social pressure to comply, but they also help developing mutual trust. A centralized network is characterized by more open structures, i.e. two friends of a friend will not necessarily also be friends, and that some actors are much more connected (central) than others (59, 61)(Fig. 1B). These open and sparser structures facilitate coordination without necessitate actors to invest lots of resources in upholding a relatively high number of social ties. These network characteristics are also conceived as representing bonding versus bridging social capital, respectively (22).

\section{Temporal or long-term problems}

Often collaborative governance arrangements are initiated in order to address long-term environmental problems, such as climate change (63). Unless such collaborative processes are provided with funding and support over significant time frames, they will rarely be able to accomplish anything substantial (20). If, however, collaborative networks are sustained over time they can lead to the cultivation and maintenance of common norms and routine deliberation (64), which are key factors in addressing long term environmental problems (18).

Transient environmental problems, however, such as eradicating a specific invasive species or stopping an escalating wildfire, require a rapid response. Thus, they might be better addressed through a rapid mobilization of relevant actors in ad-hoc collaborative networks. Furthermore, since time is often scarce, accomplishing effective coordination is of highest priority. Therefore, more centralized networks, where some specific actors act as the spiders in the web distributing and coordinating tasks, are favorable (60)(Fig. 1B). On the other hand, such network structures are less suited to addressing cooperation problems (61). Accordingly, unless the collective action problem itself is only about coordinating actors all agreeing on what needs to be done, centralized ad-hoc networks will be more effective if they are drawn from underlying and more permanent collaborative networks where mutual trust and willingness to comply is already well established $(64,65)$. This illustrates an interplay between the formation of effective and centralized ad-hoc collaborative networks and underlying, dense, and more long-lasting collaborative networks.

\section{Fit to the ecological context}

Not only should a collaborative network fit the specifics of the collective action problem, it should also fit underlying biophysical characteristics. On a conceptual level, social-ecological fit implies that the structure of a collaborative network (the actors and their collaborative ties) should be aligned with the structures of the biophysical (ecological) system being governed. However, to advance such a blanket statement, there is a need to more precisely define what would be a favorable fit, and why. This involves addressing two broad questions, namely who should ideally be involved in a collaborative network, and with whom should they ideally collaborate? Appropriate answers to these questions are, from the perspective of social-ecological fit, inherently related to the characteristics of the underlying biophysical system. Several recent and complementary network-centric frameworks facilitate answering these questions (45-48). These frameworks depart from a multilevel network approach where the social and the ecological systems are represented as separate but interconnected network layers. The social network layer consists of actors and their relationships, and the ecological network layer describes the ecosystem as sets of interdependent ecological components (Fig. 2). Using such a social-ecological 
network representation of a collaborative environmental governance arrangement, it is possible to distinguish two dimensions of social-ecological fit, namely horizontal and vertical fit. The former is concerned with how well social and ecological network ties are aligned across the layers, whereas the latter is concerned with how the different social- and ecological layers are interconnected.

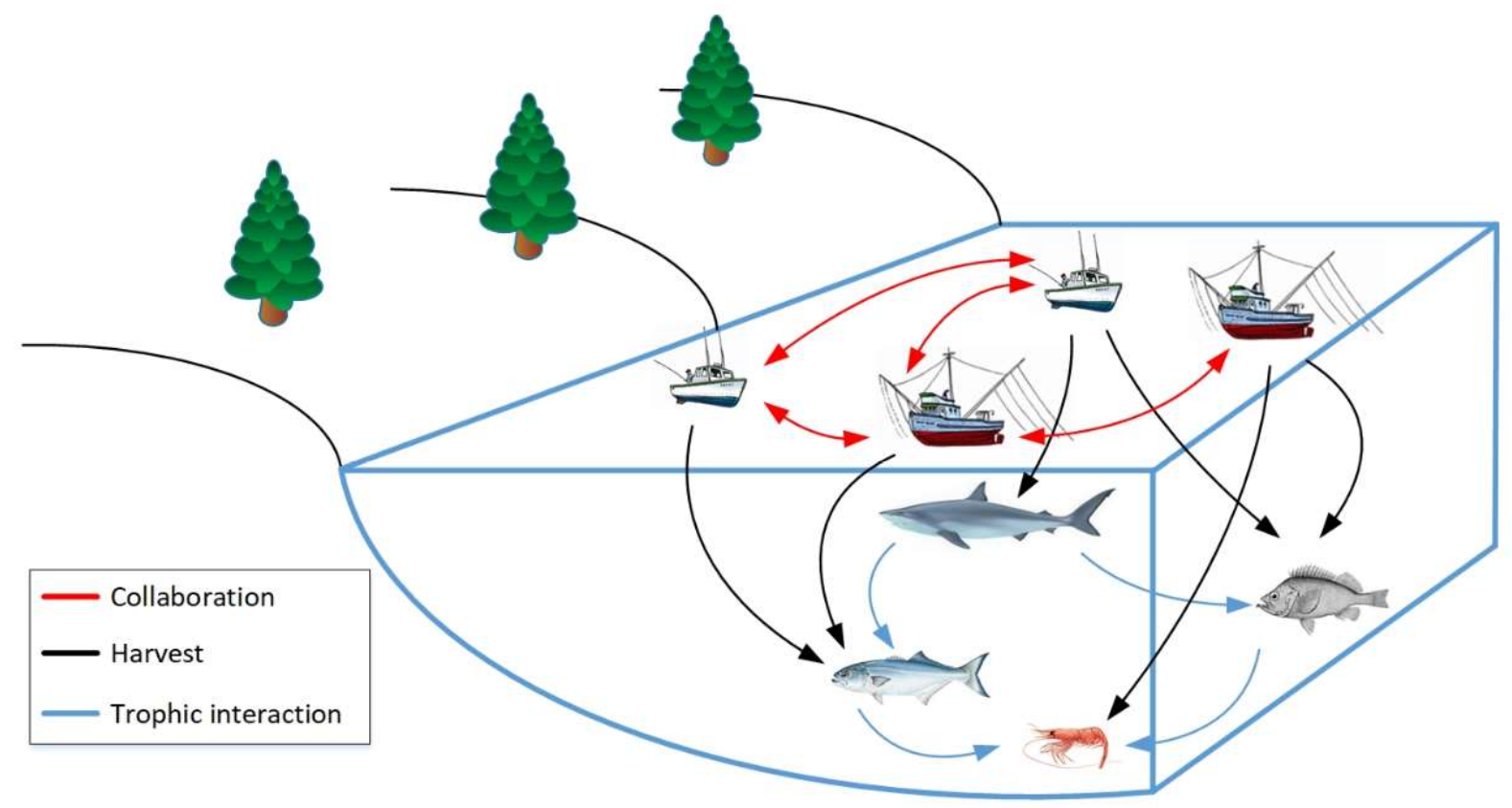

Fig. 2: A social-ecological network model of an integrated social-ecological system. The multilevel network modeling approach is illustrated using a stylized small-scale fishery system, where actors are represented by fishing vessels (social nodes), and ecological components are represented by different targeted fish species (ecological nodes). The horizontal red links represent collaborative ties, the horizontal blue links represent trophic interaction among the fish species, and the black links capture which vessel is targeting which fish species (these vertical links thus capture how different actors have different stakes in different components of the ecosystem). The modeling approach can be used to model other systems. For example, the social nodes could constitute individuals, groups, organizations or any other abstraction of an actor or "governing entity", and the ecological nodes could constitute other biophysical entities such as habitat patches, or more abstract ecological entities (48) such as ecosystem services (47).

\section{Horizontal fit}

Ecosystems consist of interdependent components. These ecological interdependencies are fundamental for the functioning of ecosystems, and compromising ecological connectivity will threaten the ability of ecosystems to provide the ecosystem services societies are relying upon $(9,66)$. Hence, the maintenance of these links is crucial. However, this is often a challenging task when human use of natural resources increases. This becomes particularly challenging if any two interdependent ecological components are managed by different actors not coordinating their managing activities. An example of such mismanagement would be when two actors each managing separate forest patches fail to manage their lands in order to facilitate species dispersals, which could threaten a common forest-dwelling meta-population whose viability depends on its ability to freely relocate between the patches (67). 
Studies of Balinese farmers, on the other hand, demonstrate how they, through collaboration, collectively reduce the spreading of pests across their ecologically interconnected rice fields by synchronizing their water use (68). Thus, this implies that a better social-ecological fit is accomplished if links in the ecological network are paired with links in the collaborative network. This can be described using the notion of social-ecological building blocks, see Fig. 3A. A social-ecological building block represent a minimal set of actors and ecological components, and their different types of interdependencies (links), that describes a theoretically important configuration of actors and ecological resources. Analogous to regression analysis, by using multilevel exponential random graph models (ERGM), it is furthermore possible to statistically infer if and to what extent different building blocks explain empirically observed structural characteristics of social-ecological (multilevel) networks $(46,69)$.

A similar argument based on alignment can be applied to cases when two actors are managing (or competing for) the same ecological component (Fig. 3B). In such cases, the utility of collaboration is even more pronounced, especially if both actors are using the shared component for extractive purposes. In such a setting, it might be rational for the actors to extract as much of the resource as they can to safeguard themselves from being left with nothing if the other actor was to maximize its extractions. This typically leads to overharvesting and resource depletion, unless resource extraction is strictly regulated and enforced by a third party (e.g. public authorities) and/or the resources are privatized (70). Such measures are often neither practically feasible nor even desired. Hence, if the actors are to avoid depleting their common resource, they need to collaborate in order to devise and enforce commonly agreed upon regulations and harvesting practices $(18,71)$.

A

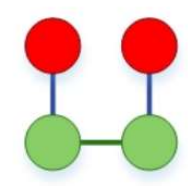

C
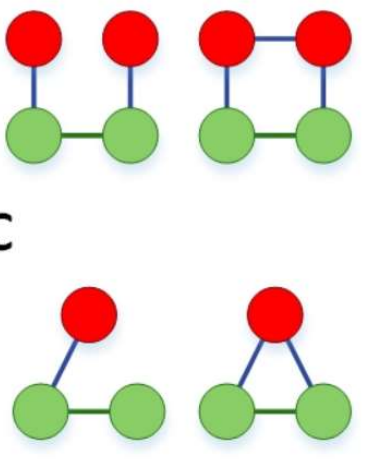

B

D

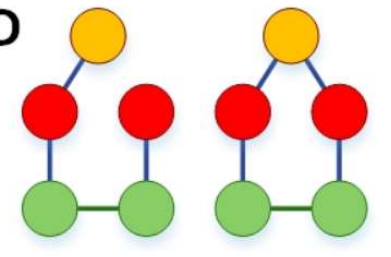

Fig. 3: Social-ecological building blocks. (A-B) Horizontal fit, i.e. alignment of social and ecological connectivity. (A) To the left, two actors (red) managing two separate but interconnected ecological components (green) are not collaborating, whereas to the right they collaborate. (B) To the left, two actors managing the same ecological component do not collaborate, whereas to the right they do. (C-D) Vertical fit across different network layers. (C) To the left, the actor is managing one of two interconnected ecological components, whereas to the right the actor is managing both components thus internalizing ecological externalities ("closing the social-ecological loop"). (D) To the left, the actors managing interconnected components are not collaborating (as in A, left), nor are both of them collaborating with the potentially mediating actor operating on a higher administrative level (orange). To the right, the vertical cross-level social ties of the mediating actor indirectly connect the two other actors. 
These theoretically derived arguments in favor of certain social-ecological building blocks have recently been exposed to empirical case studies. Even though this interdisciplinary research is still in its infancy, some insights are starting to emerge. Results from studies of a large-scale biodiversity conservation initiative in Australia and a small-scale fisheries in east Africa indicate that collaborative networks where actors with stakes in common ecological components tend to collaborate (Fig. 3B) are associated with better preservation of ecological resources and more effective management $(42,72)$. Results are so far less conclusive when it comes to the building block encapsulating the alignment of social and ecological connectivity (Fig $3 \mathrm{~A}$ ). Case studies ranging from local scales, such as inter-municipality collaboration on wetland management, to global scales, such as species dispersals across the territories of states, suggest that actors do not collaborate with others in the management of ecologically interconnected resources more than would be expected by chance $(46,72-74)$. Reasons could range from legal obstacles preventing actors from collaborating across jurisdictions (7), to a lack of comprehension in regards to the existence of ecological interdependencies (75). Furthermore, more empirical inquires of whether or not the alignment of social and ecological connectivity would leads to more desirable ecological outcomes are needed.

\section{Vertical fit}

A well-fitting collaborative network does not only entail aligning patterns of social and ecological connectivity. As stated, ecosystems should favorably be managed as systems and not as sets of isolated components, hence the patterns in which the actors are tied to the ecological components are of crucial importance. A social-ecological building block representation of vertical misfit is when an actor only manages a fraction of the ecosystem, i.e. just one of two interconnected ecological components (Fig. 3C). An example of such misfit is when landscapes are divided into different administrative, ownership, or management categories. This implies that different actors will be in charge of different categories, although the categories themselves are merely capturing different components and/or aspects of the coherent landscape (therefore, they are ecologically interdependent). Nonetheless, this division of the landscape into different components is likely to facilitate habitat change and therefore the fragmentation of contiguous land covers (76).

A tighter feedback loop between an actor's managing activities and whatever environmental outcomes these activities give rise to on an ecosystem level is, however, accomplished If the actor is linked to both components (Fig. 3C). This is also referred to as scale matching (5). In economic terms, this implies that potential ecological externalities have been internalized (42). Emerging insights suggest this building block is more common in collaborative networks performing reasonably well $(42,72)$, although empirical research investigating whether or not collaborative networks experience this type of vertical fit is still very scarce.

Actors are often situated at different administrative levels. These levels typically correspond to different geographical scales (cf. local resource extractors and regional managers). Many ecological processes interact across scales, therefore social ties linking actors across these administrative levels implies a better alignment of collaborative structures and ecological cross-scale interdependences (45). Hence, vertical cross-level social ties indirectly linking actors at the same administrative levels could enhance horizontal social-ecological alignment (Fig. 3D). In a study of collaborative inter-municipality wetland management it was found that a variety of social-ecological building blocks resembling the idea of coordinating actors indirectly linking two other actors were overrepresented in the collaborative network, suggesting that actors have a propensity to engage in collaborative structures where coordination is facilitated through a third party (77). Further, a study of estuary watershed governance indicated that actors' perceptions of the productivity of social ties linking local and regional levels were positively affected by their abundance, although the study also revealed that such an effect was 
intertwined with other network effects (45). However, the arguments behind the presumed benefits of linking levels are not limited to studies using an explicit social-ecological network representation of actors and ecological components. The core arguments presented here largely resemble some of the presumed benefits of polycentric governance (78), and the utility of scale-crossing and multilevel environmental governance more generally $(6,79,80)$. Thus, the theoretical and empirical basis supporting the presumed benefits of cross-level collaborative ties is quite substantial.

\section{Compounded environmental problems}

Environmental problems are often best described as aggregates of more or less interdependent subproblems (cf. , 81), hence simultaneously displaying a range of collective action problem characteristics. For example, even though cooperation and coordination seemingly benefit from rather different network structures (Fig. 1A-B), empirical collaborative networks tend to display both types of structures $(40,59,62,82,83)$. Thus, it appears that collaborative networks are often formed in response to both types of collective action problems, although it should also be weighted in that actors do not exclusively create social ties based on the nature of the collective action problem (cf. , 22). Furthermore, the problem specifics of an environmental issue will likely change over time. This implies that what might constitute an effective collaborate network should also change over time (39). Among dairy farmers in the eastern United States, it has been shown that the build-up of weak social ties was integral in the enablement of a transformation to new and novel farming practices, although it was also shown that farmers did not maintain these weak relationships after they had transformed (84). Hence, after the transformation, these weak ties were likely no longer needed. A longitudinal study of climate change mitigation policy development in Switzerland further demonstrated that the policy networks changed notably between the decision-making and the implementation phases (85).

Taken together, all this suggests that multipurpose collaborative networks that are able to address a range of collective action problems, and that can adapt to changes in the nature of these problems, are better suited to addressing environmental problems. What is less known is, however, if being fit to various collective action problems and being fit to the ecological context constitute two independent dimensions of fit. Claims conceptually favoring interdependency abound, signified by the establishment of several widely used frameworks emphasizing the need for integrated social-ecological systems perspectives (e.g. , 10). Ongoing attempts to mitigate climate change serve as an illustration. Climate change mitigation appears to struggle in comparison with, for example, the success of the multi-lateral treaty that swiftly reduced the emission of substances that deplete the Ozone layer. Both these environmental problems are similar in that they engage many states in tough negotiations. Nonetheless, they deviate in performance. Such deviations are regularly attributed to contextual social-ecological differences. A social-ecological network perspective can help disentangling some of these socialecological contextual differences into clearly articulated, theoretically grounded, and measurable characteristics specifying ways in which actors and the environment are entangled. Bringing the socialecological and collaborative network perspectives together in a unifying framework could therefore facilitate integrated studies where 'classic' collective action problems (learning, coordination, cooperation, etc.) and social-ecological fit are analyzed together.

An important question for further research should, for example, be if and how the utility of collaborative network structures conducive for solving coordination problems (Fig. 1B) depends on how social and ecological connectivity is aligned horizontally and vertically (Fig. 3). Such research endeavors would contribute in unpacking the social-ecological context and more precisely investigate potential causal pathways in which social-ecological interdependencies influencing actors' abilities to solve collective action problems of various kinds. A study of the relatively effective management response following the 
establishment of the invasive Indo-Pacific Lionfish (Pterois miles and Pterois volitans) across a set of marine protected areas (MPA) in Jamaica serves as an illustration of research pointing in that direction (86). Due to the high ecological connectivity among the MPAs, an effective response required all MPA managers to apply adequate eradicative measures to their sites simultaneously. Hence, there was no need to adhere to any specific sequence of eradiation across the MPA sites. Devising and implementing a sequential response among a large set of local MPA managers would likely have required more coordination effort than just agreeing on a common starting time. Hence, the need for thorough horizontal coordination among the managers was lowered. The study furthermore suggests that the managers' synchronized responses was made possible largely due to a high level of cross-level connectivity, i.e. the local managers were well connected with higher level authorities that coordinated their response. This corresponds to the social-ecological building block where a mediating actor facilitate collaboration between any two actors managing two interconnected ecological components (Fig. 2D). Therefore, due to the high ecological connectivity, vertical cross-level coordination seemingly became more important than horizontal coordination (Fig. 1B, inset) in enabling an effective response to this specific environmental problem.

\section{Collaborative networks and leadership}

Collaborative networks are made up of actors with different capabilities, interests, and intentions. Hence, the effectiveness of collaborative environmental governance in addressing environmental problems can only partly be understood from a structural collaborative network perspective. For example, a highly centralized network conducive to efficient coordination (Fig. 1B) might still fail if the centrally located coordinator is not doing his/her job. Hence, the effectiveness of a collaborative network results from the interplay between the overall structure of the network, the characteristics of its actors, and the network positions which they occupy. Studies of small-scale fisheries have, for example, shown that the utility of coherent collaborate networks conducive for cooperation is amplified if suitable leadership is in place $(87,88)$. Recent research further suggests that effective collaborative environmental governance requires a range of different leadership qualities (cf. , 24). Below some leadership qualities that are strongly related to the structure and functioning of collaborative networks are discussed.

\section{Network positions and leadership qualities}

The crucial importance of spanning boundaries (also referred to as bridging or brokerage) is emphasized in research and practice. A boundary-spanner connects different types of actors, and/or organizationaland biophysical levels and scales (cf. vertical social-ecological fit discussed earlier) that would otherwise be disconnected or only weakly connected (89). In network terms, a boundary-spanner occupies a position in-between many others, spanning structural holes in the network (89). Leadership executed by boundary-spanners has, for example, been shown to increase mutual trust $(16,17)$, and to help build adequate support in attempts to address environmental problems through far-reaching transformational changes in management and perceptions $(24,90)$. However, it has also been demonstrated that boundary-spanners might utilize their position mostly for personal benefits (89); they might hold certain perceptions and attitudes that can impede success in collaborative endeavors (28), or, although they may contribute positively to collaborative outcomes, they themselves might be penalized (91).

Central actors, i.e. the ones that have significantly more social ties than others, are well situated to execute leadership that facilitates collective action. Their central position facilities coordination of activities, but also synthesizing others' insights and perceptions to facilitate collective sense-making (e.g. ,24), and the diffusing of new ideas and practices (53). Moreover, central actors occupy a position well 
suited for helping to bridge across different boundaries (through the sheer number of ties, which is not the same as occupying a boundary-spanning position $)(40,92)$. However, as previously stated, these presumed benefits deriving from occupying a central position are inherently tied to the centrally positioned actors' leadership skills, how they are perceived by others, and which resources they have at their disposal. Cognitive limitations, for example, pose constraints on the amount of coordination that can effectively be carried out (93). It has been demonstrated that appointing (and funding) a specifically designated coordinator, a Network Administrative Organization (NAO), can be instrumental in realizing the potential benefits that occupying a central position in the collaborative network can bring about (17, $21,60,94)$. Furthermore, it has been suggested that effective coordination is benefitted by the central actors being able to exert some pressure on others to comply, hence it is beneficial if they possess some authoritative capacities (59).

Studies have shown that some specific actors who are engaged in collaborative endeavors act as "risk mediators" in that they tend to occupy network positions associated with tight bonding structures (62)(inset in Fig. 1A). Thus, managing risks in collaborative undertakings can be thought of as a division of labor where some actors execute leadership specifically intended to mediate risky relationships, thereby enabling others to allocate more attention to less risk-prone collaborative endeavors (e.g. coordination). For example, a study of collaborative urban development planning revealed that state agencies did most of the "heavy-lifting" in managing risks in various collaborative relationships (62).

\section{Network weaving}

Collaborative networks, like other social networks, are not static; they continually evolve as actors adjust to different endogenous and exogenous drivers of change. Hence, different network structures do not emerge by chance, nor are positions within the network distributed randomly. Developing a better understanding of collaborative network dynamics thus involves identifying the mechanisms that make certain actors engage in collaboration with certain others, as well as identifying what it is that makes it more or less attractive to engage with certain actors (e.g. , 85). This touches upon yet another dimension of leadership in collaborative endeavors, i.e. how leaders directly or indirectly engage in creating, intervening and shaping networks ("network weaving", see $(46,90,95,96))$. The formation of network ties can, for example, be stimulated through direct engagement, or through establishing collaborative venues (often referred to as collaborative institutions). The former is about engaging directly with other actors, potentially through brokering. The latter is about convening the formation of ties through the establishment of collaborative venues where actors are invited to collaborate in addressing certain predefined issues and problems (1). Actors might be mandated to participate in these venues, or participation could be voluntary. Depending on the context, the size of a venue could range from village meetings where local fishermen gather to discuss fishing practices to multinational collaborative platforms such as the intergovernmental panel on climate change (IPCC). Contemporary environmental governance systems are often characterized by a high number of venues (e.g. , 97). For example, a study of water governance in San Francisco Bay, California, showed that the number of actors and venues were both measured in the hundreds (82). In such settings, largely resembling polycentric governance systems where decision-making is distributed across multiple fora, the collaborative arenas confronting actors and stakeholders are not only made up of many other actors and their social ties, they also span multiple venues and multiple policy issues; all potentially interdependent in complex ways $(1,98)$. How this complex "ecology of games" impacts collaborative environmental governance has stirred up scholarly interests. Early findings suggest that the more venues individual actors participate in, the higher they tend to perceive venue effectiveness and the amount of resources they can derive from venue participation $(99,100)$, although broad venue participation can, for example, also negatively influence policy satisfaction (1). 


\section{Conclusion and outlook}

Much is known about collaborative networks and how they tend to be formed and shaped. However, merely establishing a collaborative network does in no way guarantee that environmental problems will be effectively addressed. Future efforts are needed to determine when and in what contexts collaborative approaches are most effective, and when other approaches to solve environmental problems are better suited.

The path forward involves addressing a range of critical research questions. Our understanding of how certain collaborative network structures contribute to different governance outcomes, and how they interact with different aspects of agency and leadership, is at present often indicative. Further, research on how collaborative governance arrangements are more or less well-fitted to various characteristics of the ecosystems, and what this implies for governance outcomes, is very scarce. In particular, if and how being fit to the specifics of the collective action problem and being fit to the ecological context interact is largely uncharted territory. Assessing such entangled casual relationships between collaborative environmental governance, social-ecological fit, and governance outcomes requires further advancements of contemporary interdisciplinary theories and methods.

Environmental problems are often composed of a series of different kinds of interdependent collective action problems. However, more efforts are needed if we are to understand if and how collaborative networks encompassing a matching set of desirable structural characteristics conducive to addressing this range of problems can be created and maintained. To be both socially and ecologically fit to the environmental problems at hand, such multifunctional and multipurpose collaborative networks would need to strike a favorable balance between many 'ideal' and often contradicting structural characteristics. This calls for further efforts to advance unconventional forms of public and private leadership more focused on "network weaving" and facilitation, and less on command and control (Table 1).

Table 1: Management challenges in collaborative environmental governance

\begin{tabular}{|l|}
\hline - How to create and maintain collaborative networks that are able to address tough \\
problems involving deep-rooted conflicts of interests while simultaneously being \\
conducive to the efficient coordination of relatively simple tasks?
\end{tabular}

Furthermore, collaborative governance initiatives are often established as projects, with funding for a limited time (20). The underlying environmental problems, however, are often more enduring, hence a fundamental challenge is to better understand how collaborative endeavors can be better adopted by formal bureaucracies and incorporated into existing government structures and processes. 
Many of the most pressing and complex environmental problems of today operate at regional and global scales. Furthermore, instigating and maintaining effective collaboration might be the only feasible option to address environmental problems at these scales. A substantial part of current research of collaborative networks in environmental governance is however conducted on smaller scales. This suggest more research efforts should be directed towards the regional and global scales.

\section{References and Notes}

1. M. Lubell, Governing Institutional Complexity: The Ecology of Games Framework. Policy Stud. J. 41, 537-559 (2013).

2. O. R. Young, The institutional dimensions of environmental change: fit, interplay, and scale (MIT Press, Cambridge, Massachusetts, USA, 2002).

3. V. Galaz, T. Hahn, P. Olsson, C. Folke, U. Svedin, in Institutions and Environmental Change: Principal Findings, Applications, and Research Frontiers, O. R. Young, H. Schroeder, L. A. King, Eds. (MIT Press, Cambridge, 2008), pp. 147-186.

4. G. Epstein et al., Institutional fit and the sustainability of social-ecological systems. Curr. Opin. Environ. Sustain. 14, 34-40 (2015).

5. G. S. Cumming, D. H. M. Cumming, C. L. Redman, Scale mismatches in social-ecological systems: causes, consequences, and solutions. Ecol. Soc. 11, 14 (2006).

6. J. Edelenbos, I. van Meerkerk, Connective capacity in water governance practices: The meaning of trust and boundary spanning for integrated performance. Curr. Opin. Environ. Sustain. 12, 2529 (2015).

7. B. A. Cosens, Legitimacy, Adaptation, and Resilience in Ecosystem Management. Ecol. Soc. 18, 3 (2013).

8. B. Walker et al., Looming global-scale failures and missing institutions. Science (80-. ). 325, 13451346 (2009).

9. N. L. Christensen et al., The Report of the Ecological Society of America Committee on the Scientific Basis for Ecosystem Management. Ecol. Appl. 6, 665-691 (1996).

10. C. Folke, T. Hahn, P. Olsson, J. Norberg, Adaptive Governance of Social-Ecological Systems. Annu. Rev. Environ. Resour. 30, 441-473 (2005).

11. M. S. Reed et al., What is Social Learning ? Ecol. Soc. 15, r1 (2010).

12. M. Tengö, E. S. Brondizio, T. Elmqvist, P. Malmer, M. Spierenburg, Connecting Diverse Knowledge Systems for Enhanced Ecosystem Governance: The Multiple Evidence Base Approach. Ambio. 43, 579-591 (2014).

13. P. Matouš, Y. Todo, D. Mojo, Roles of extension and ethno-religious networks in acceptance of resource-conserving agriculture among Ethiopian farmers. Int. J. Agric. Sustain., 1-16 (2012).

14. P. A. Sabatier, An advocacy coalition framework of policy change and the role of policy-oriented learning therein. Policy Sci. 21, 129-168 (1988). 
15. M. Fischer, Coalition Structures and Policy Change in a Consensus Democracy. Policy Stud. J. 42, 344-366 (2014).

16. I. van Meerkerk, J. Edelenbos, The effects of boundary spanners on trust and performance of urban governance networks: Findings from survey research on urban development projects in the Netherlands. Policy Sci. 47, 3-24 (2014).

17. H. Österblom, Ö. Bodin, Global Cooperation among Diverse Organizations to Reduce Illegal Fishing in the Southern Ocean. Conserv. Biol. 26, 638-648 (2012).

18. T. Dietz, E. Ostrom, P. C. Stern, The Struggle to Govern the Commons. Science (80-. ). 302, 19071912 (2003).

19. T. M. Koontz, C. W. Thomas, What Do We Know and Need to Know about the Environmental Outcomes of Collaborative Management? Public Adm. Rev. 66, 111-121 (2006).

20. J. Munck af Rosenschöld, N. Honkela, J. I. Hukkinen, Addressing the temporal fit of institutions: the regulation of endocrine-disrupting chemicals in Europe. Ecol. Soc. 19 (2014), doi:10.5751/ES07033-190430.

21. J. Raab, R. S. Mannak, B. Cambre, Combining Structure, Governance, and Context: A Configurational Approach to Network Effectiveness. J. Public Adm. Res. Theory. 25, 479-511 (2015).

22. A. D. Henry, M. Lubell, M. McCoy, Belief Systems and Social Capital as Drivers of Policy Network Structure: The Case of California Regional Planning. J. Public Adm. Res. Theory. 21, 419-444 (2011).

23. E.-H. Klijn, C. Skelcher, Democracy and Governance Networks: Compatible or Not? Public Adm. 85, 587-608 (2007).

24. F. R. Westley et al., A Theory of Transformative Agency in Linked Social-Ecological Systems. Ecol. Soc. 18, 27 (2013).

25. E.-H. Klijn, B. Steijn, J. Edelenbos, The Impact of Network Management on Outcomes in Governance Networks. Public Adm. 88, 1063-1082 (2010).

26. M. Shellenberger, T. Nordhaus, The Death of Environmentalism. Geopolit. Hist. Int. Relations. 1, 121 (2009).

27. A. Zachrisson, K. Beland Lindahl, Conflict resolution through collaboration: Preconditions and limitations in forest and nature conservation controversies. For. Policy Econ. 33, 39-46 (2013).

28. T. A. Muñoz-erickson et al., Spanning Boundaries in an Arizona Watershed Partnership: Information Networks as Tools for Entrenchment or Ties for Collaboration? Ecol. Soc. 15, 22 (2010).

29. A. P. Castro, E. Nielsen, Indigenous People and Co-management: Implications for Conflict Management. Environ. Sci. Policy. 4, 229-239 (2001).

30. P. A. Walker, P. T. Hurley, Collaboration Derailed: The Politics of "Community-Based" Resource Management in Nevada County. Soc. Nat. Resour. 17, 735-751 (2004).

31. R. F. Brummel, K. C. Nelson, P. J. Jakes, Burning through organizational boundaries? Examining 
inter-organizational communication networks in policy-mandated collaborative bushfire planning groups. Glob. Environ. Chang. 22, 516-528 (2012).

32. T. A. Scott, C. W. Thomas, Unpacking the Collaborative Toolbox: Why and When Do Public Managers Choose Collaborative Governance Strategies? Policy Stud. J. 0, 1-24 (2016).

33. C. Ansell, A. Gash, Collaborative Governance in Theory and Practice. J. Public Adm. Res. Theory. 18, 543-571 (2007).

34. R. R. J. McAllister, R. McCrea, M. N. Lubell, Policy networks, stakeholder interactions and climate adaptation in the region of South East Queensland, Australia. Reg. Environ. Chang. 14, 527-539 (2014).

35. D. Nohrstedt, Ö. Bodin, Evolutionary Dynamics of Crisis Preparedness Collaboration: Resources, Turbulence and Network Change in Swedish Municipalities. Risk, Hazards Cris. Public Policy. 5, 134-155 (2014).

36. B. Nykvist, Does Social Learning Lead to Better Natural Resource Management? A Case Study of the Modern Farming Community of Practice in Sweden. Soc. Nat. Resour., 1-15 (2014).

37. P. Matous, Y. Todo, Exploring dynamic mechanisms of learning networks for resource conservation. Ecol. Soc. 20, 36 (2015).

38. A. D. Henry, B. Vollan, Networks and the Challenge of Sustainable Development. Annu. Rev. Environ. Resour. 39, 583-610 (2014).

39. Ö. Bodin, B. I. Crona, The role of social networks in natural resource governance: What relational patterns make a difference? Glob. Environ. Chang. 19, 366-374 (2009).

40. Ö. Bodin, A. Sandström, B. Crona, Collaborative Networks for Effective Ecosystem-Based Management: A Set of Working Hypotheses. Policy Stud. J. 45, 289-314 (2017).

41. R. Plummer et al., Is Adaptive Co-management Delivering? Examining Relationships Between Collaboration, Learning and Outcomes in UNESCO Biosphere Reserves. Ecol. Econ. 140, 79-88 (2017).

42. Ö. Bodin, B. Crona, M. Thyresson, A.-L. Golz, M. Tengö, Conservation Success as a Function of Good Alignment of Social and Ecological Structures and Processes. Conserv. Biol. 28, 1371-1379 (2014).

43. C. S. Holling, G. K. Meffe, Command and control and the pathology of natural resource management. Conserv. Biol. 10, 328-337 (1996).

44. C. Folke, L. Pritchard, F. Berkes, J. Colding, U. Svedin, The problem of fit between ecosystems and institutions: ten years later. Ecol. Soc. 12, 30 (2007).

45. J. S. Sayles, J. A. Baggio, Social-ecological network analysis of scale mismatches in estuary watershed restoration. Proc. Natl. Acad. Sci., 201604405 (2017).

46. Ö. Bodin et al., Theorizing benefits and constraints in collaborative environmental governance: a transdisciplinary social-ecological network approach for empirical investigations. Ecol. Soc. 21, 40 (2016).

47. L. E. Dee et al., Operationalizing Network Theory for Ecosystem Service Assessments. Trends Ecol. 
Evol. 32, 118-130 (2017).

48. J. A. Ekstrom, O. R. Young, Evaluating Functional Fit between a Set of Institutions and an Ecosystem. Ecol. Soc. 14, 16 (2009).

49. K. Ingold, Network Structures within Policy Processes: Coalitions, Power, and Brokerage in Swiss Climate Policy. Policy Stud. J. 39, 435-459 (2011).

50. C. T. Gallemore, R. D. Prasti H., M. Moeliono, Discursive barriers and cross-scale forest governance in Central Kalimantan, Indonesia. Ecol. Soc. 19, 18 (2014).

51. L. Jasny, J. Waggle, D. R. Fisher, An empirical examination of echo chambers in US climate policy networks. Nat. Clim. Chang., 1-5 (2015).

52. M. L. Barnes, J. Lynham, K. Kalberg, P. Leung, Social networks and environmental outcomes. Proc. Natl. Acad. Sci. (2016), doi:10.1073/pnas.1523245113.

53. T. W. Valente, Network interventions. Science (80-. ). 337, 49-53 (2012).

54. M. E. Isaac, Agricultural information exchange and organizational ties: The effect of network topology on managing agrodiversity. Agric. Syst. 109, 9-15 (2012).

55. F. Westley et al., Tipping Toward Sustainability: Emerging Pathways of Transformation. Ambio, 16-19 (2011).

56. B. Uzzi, J. Spiro, Collaboration and Creativity: The Small World Problem. Am. J. Sociol. 111, 447504 (2005).

57. A.-M. Dowd et al., The role of networks in transforming Australian agriculture. Nat. Clim. Chang. 4, 558-563 (2014).

58. M. Granovetter, The strength of weak ties. Am. J. Sociol. 76, 1360-1380 (1973).

59. R. Berardo, The evolution of self-organizing communication networks in high-risk socialecological systems. Int. J. Commons. 8, 236-258 (2014).

60. M. Lubell, L. Jasny, A. Hastings, Network Governance for Invasive Species Management. Conserv. Lett. (2016), doi:10.1111/conl.12311.

61. R. Berardo, J. T. Scholz, Self-Organizing Policy Networks: Risk, Partner Selection, and Cooperation in Estuaries. Am. J. Pol. Sci. 54, 632-649 (2010).

62. R. R. J. McAllister, B. M. Taylor, B. P. Harman, Partnership Networks for Urban Development: How Structure is Shaped by Risk. Policy Stud. J. 43, 379-398 (2015).

63. R. Grundmann, Nat. Geosci., in press, doi:10.1038/ngeo2780.

64. C. L. Meek, Forms of collaboration and social fit in wildlife management: A comparison of policy networks in Alaska. Glob. Environ. Chang. (2012), doi:10.1016/j.gloenvcha.2012.10.003.

65. A. Boin, P. 't Hart, Organising for Effective Emergency Management: Lessons from Research. Aust. J. Public Adm. 69, 357-371 (2010).

66. R. Biggs, M. Schlüter, M. L. Schoon, Principles for Building Resilience: Sustaining ecosystem services in social-ecological systems (Cambride University Press, Cambridge, 2014). 
67. I. Chadès et al., General rules for managing and surveying networks of pests, diseases, and endangered species. Proc. Natl. Acad. Sci. U. S. A. 108, 8323-8328 (2011).

68. J. S. Lansing, J. N. Kremer, Emergent Properties of Balinese Water Temple Networks: Coadaptation on a Rugged Fitness Landscape. Am. Anthropol. 95 (1993).

69. P. Wang, G. Robins, P. Pattison, E. Lazega, Exponential random graph models for multilevel networks. Soc. Networks. 35, 96-115 (2013).

70. G. Hardin, The Tradgedy of the Commons. Science (80-. ). 162, 1243-1248 (1968).

71. E. Ostrom, Governing the Commons: The Evolution of Institutions for Collective Action (Cambridge University Press, 1990).

72. A. M. Guerrero, Ö. Bodin, R. R. J. McAllister, K. A. Wilson, Achieving social-ecological fit through bottom-up collaborative governance: an empirical investigation. Ecol. Soc. 20, 41 (2015).

73. E. Treml, P. I. J. Fidelman, S. Kininmonth, J. Ekstrom, Ö. Bodin, Analyzing the (mis)fit between the institutional and ecological networks of the Indo-West Pacific. Glob. Environ. Chang. 31, 263-271 (2015).

74. A. Bergsten, D. Galafassi, Ö. Bodin, The problem of spatial fit in social-ecological systems: detecting mismatches between ecological connectivity and land management in an urban region. Ecol. Soc. 19, 6 (2014).

75. A. Bergsten, A. Zetterberg, To model the landscape as a network: A practitioner's perspective. Landsc. Urban Plan. 119, 35-43 (2013).

76. M. Dallimer, N. Strange, Why socio-political borders and boundaries matter in conservation. Trends Ecol. Evol. 30, 132-139 (2015).

77. S. Kininmonth, A. Bergsten, Ö. Bodin, Closing the collaborative gap: Aligning social and ecological connectivity for better management of interconnected wetlands. Ambio. 44, 138-148 (2015).

78. E. Ostrom, A Long Polycentric Journey. Annu. Rev. Polit. Sci. 13, 1-23 (2010).

79. C. Wyborn, R. P. Bixler, Collaboration and nested environmental governance: Scale dependency, scale framing, and cross-scale interactions in collaborative conservation. J. Environ. Manage. 123, 58-67 (2013).

80. K. Maciejewski, A. De Vos, G. S. Cumming, C. Moore, D. Biggs, Cross-scale feedbacks and scale mismatches as influences on cultural services and the resilience of protected areas. Ecol. Appl. 25, 11-23 (2015).

81. Ö. Bodin, D. Nohrstedt, Formation and performance of collaborative disaster management networks: Evidence from a Swedish wildfire response. Glob. Environ. Chang. 41, 183-194 (2016).

82. M. Lubell, G. Robins, P. Wang, Network structure and institutional complexity in an ecology of water management games. Ecol. Soc. 19, 23 (2014).

83. R. R. J. Mcallister, C. J. Robinson, K. Maclean, S. Perry, S. Liu, Balancing collaboration with coordination: Contesting eradication in the Australian plant pest and disease biosecurity system. Int. J. commons. 11 (2017), doi:10.18352/ijc.701.

84. K. C. Nelson, R. F. Brummel, N. Jordan, S. Manson, Social networks in complex human and natural 
systems: the case of rotational grazing, weak ties, and eastern US dairy landscapes. Agric. Human Values. 31, 245-259 (2014).

85. K. Ingold, M. Fischer, Drivers of collaboration to mitigate climate change: An illustration of Swiss climate policy over 15 years. Glob. Environ. Chang. 24, 88-98 (2014).

86. S. M. Alexander, D. Armitage, P. J. Carrington, Ö. Bodin, Examining horizontal and vertical social ties to achieve social-ecological fit in an emerging marine reserve network. Aquat. Conserv. Mar. Freshw. Ecosyst. (2017), doi:10.1002/aqc.2775.

87. B. Crona, S. Gelcich, Ö. Bodin, The Importance of Interplay Between Leadership and Social Capital in Shaping Outcomes of Rights-Based Fisheries Governance. World Dev. 91, 70-83 (2016).

88. S. Alexander, D. Armitage, T. Charles, Social networks and transitions to co-management in three marine reserves in Jamaica. Glob. Environ. Chang. 35, 213-225 (2015).

89. R. S. Burt, Structural Holes and Good Ideas. Am. J. Sociol. 110, 349-399 (2004).

90. P. Olsson, V. Galaz, W. J. Boonstra, Sustainability transformations: a resilience perspective. Ecol. Soc. 19, 1 (2014).

91. M. Barnes, K. Kalberg, M. Pan, P. Leung, When is brokerage negatively associated with economic benefits? Ethnic diversity, competition, and common-pool resources. Soc. Networks. 45, 55-65 (2016).

92. A. Sandström, C. Rova, Adaptive co-management networks: A comparative analysis of two fishery conservation areas in Sweden. Ecol. Soc. 15, 14 (2010).

93. J. Shore, E. Bernstein, D. Lazer, Facts and Figuring: An Experimental Investigation of Network Structure and Performance in Information and Solution Spaces. Organ. Sci. 26, 1432-1446 (2015).

94. K. G. Provan, P. Kenis, Modes of Network Governance: Structure, Management, and Effectiveness. J. Public Adm. Res. Theory. 18, 229-252 (2007).

95. K. Vance-Borland, J. Holley, Conservation stakeholder network mapping, analysis, and weaving. Conserv. Lett. 4, 278-288 (2011).

96. D. G. Rand, S. Arbesman, N. a. Christakis, Dynamic social networks promote cooperation in experiments with humans. Proc. Natl. Acad. Sci. 108, 19193-19198 (2011).

97. R. Berardo, M. Lubell, Understanding What Shapes a Polycentric Governance System. Public Adm. Rev. (2016), doi:10.1111/puar.12532.

98. M. D. McGinnis, Networks of Adjacent Action Situations in Polycentric Governance. Policy Stud. J. 39, 51-78 (2011).

99. M. Lubell, J. M. Mewhirter, R. Berardo, J. T. Scholz, Transaction Costs and the Perceived Effectiveness of Complex Institutional Systems. Public Adm. Rev. xx, 1-13 (2016).

100. T. A. Scott, C. W. Thomas, Winners and Losers in the Ecology of Games: Network Position, Connectivity, and the Benefits of Collaborative Governance Regimes. J. Public Adm. Res. Theory. 31, 59 (2017). 


\section{Acknowledgements}

This work was financially supported by MISTRA through a core grant to the Stockholm Resilience Centre at Stockholm University. Furthermore, the Swedish Research Council and FORMAS contributed with additional support through the project grants 2016-04263 and 2016-01137. 